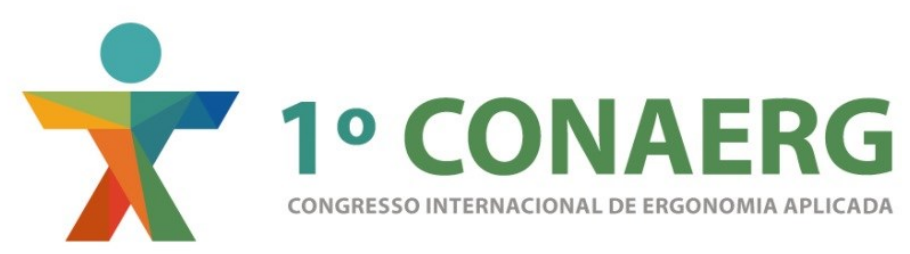

\title{
ERGONOMIA NA MANUTENÇÃO DE LINHAS DE TRANSMISSÃO DE ENERGIA ELÉTRICA - A EXPERIÊNCIA DA ELETROBRAS/ELETRONORTE
}

\author{
Marcio Robert da Silva Ribeiro (1) \\ (1) Eletrobras-Eletronorte (Regional Pará - Divisão de Vila do Conde), Especialista em \\ Gestão de Pessoas \\ e-mail: marcio.ribeiro2@eletronorte.gov.br
}

\begin{abstract}
RESUMO
O trabalho de eletricistas que atuam no sistema elétrico de potência é marcado pela presença de consideráveis demandas físicas e mentais. A atividade de manutenção em linhas de transmissão possui pouco ou quase nenhum estudo ergonômico que visa a melhora da eficiência e qualidade. Além do evidente risco de natureza elétrica, os eletricistas encontram-se expostos aos riscos de acidentes decorrentes do trabalho em altura, condições ambientais e fatores organizacionais de trabalho. Este trabalho mostra a experiência da Eletrobras/Eletronorte-Pará na implantação de melhorias na atividade de troca de espaçadores em linha viva, com o apoio do Proergo Corporativo implantado pela empresa.
\end{abstract}

Palavras chave: eletricistas; espaçadores; equilíbrio postural.

\begin{abstract}
The electricians work that operate in the electric power system is marked by the presence of considerable physical demands and mentais. A maintenance activity in transmission lines, has little or no ergonomic study aimed at improving efficiency and quality. Beyond the obvious risk of electrical nature, electricians are exposed to the risk of accidents arising from working at heights, environmental conditions and organizational factors work. Este work shows the experience of Eletrobras / Eletronorte Para in the implementation of improvements in the spacers exchange activity live line, with the support of Corporate Proergo deployed by the company.
\end{abstract}

Keywords: electricians; spacers; postural balance.

\section{INTRODUÇÃO}

A Eletrobras Eletronorte, sociedade anônima de economia mista é uma concessionária de serviço público de energia elétrica. Criada em 20 de junho de 1973, com sede no Distrito Federal, gera e fornece energia elétrica aos nove estados da Amazônia Legal - Acre, Amapá, Amazonas, Maranhão, Mato Grosso, Pará, Rondônia, Roraima e Tocantins. Por meio do Sistema Interligado Nacional - SIN, também fornece energia a compradores das demais regiões do País. Com o atual modelo do setor elétrico chegamos também ao Rio Grande do Norte e São Paulo.Temos uma capacidade de geração instalada de mais de 9 
mil MW e operamos cerca de 10.700 quilômetros de linhas de transmissão e 58 subestações para levar energia elétrica a todo Brasil por meio do Sistema Interligado Nacional - SIN.

A ergonomia estuda a adaptação recíproca entre o trabalhador e o seu trabalho e busca soluções de forma a obter o binômio conforto físico e mental para o trabalhador e a produtividade para o empregador, procurando adaptar as condições de trabalho às características do ser humano (COUTO e MORAES, 1999).

O trabalho relata o histórico, desenvolvimento, aplicação de uma nova técnica de acesso ao potencial elétrico, para a realização da atividade de troca de espaçadores (Figura 1) danificados na LT Tucuruí Vila do Conde 1 (linha de transmissão que interliga os municípios de Tucuruí e Barcarena, ambos no estado do Pará), minimizando o esforço físico do eletricista, aumentando a segurança e ampliando a produtividade da equipe de manutenção nesse tipo de atividade.

Poucos eletricistas têm capacidade física para exercer a função durante toda a vida de trabalho, pois um grande número deles apresenta lesões musculoesqueléticas após anos de exposição à atividade, principalmente devido ao uso excessivo de força (SEELEY e MARKLIN, 2003). A atividade dos eletricistas apresenta também riscos associados ao desenvolvimento de distúrbios osteomusculares relacionados ao trabalho (DORT) devido à exposição a tarefas pesadas, posturas inadequadas, manuseio de materiais e às condições climáticas variáveis por realizarem trabalho de campo (GRAVES et al., 1996) e (PAIVINEN, 2006).

Os espaçadores são componentes de uma linha de transmissão, que têm como principal função manter o espaçamento dos cabos condutores, que quando movimentados pelos ventos, oscilam, tocando-se entre si, causando desgaste e danificação mútua. São também utilizados em barramentos aéreos de subestações. Conforme a configuração do feixe e classe de tensão poderão ser duplos, triplos, quádruplos e até oitavados.

Com o uso de uma grua montada sobre a carroceria de um caminhão, que iça o eletricista confortavelmente sentado numa cadeira até o local com danos na linha.

Antes, a troca dos espaçadores era feita com uma escada pesada. Os mais hábeis percorriam os cabos andando. Em seguida, veio o uso de uma "caçamba" com roldanas, a bicicleta, que era puxada com uma corda pela equipe de solo. Uma solução ainda penosa. A bicicleta melhorou a lida, mas os equipamentos de troca dos espaçadores, as vestimentas isolantes, aquilo tudo era uma pesada parafernália, e com as altas temperaturas locais, logo o eletricista estava molhado de suor. Sem falar que a velha guarda dos eletricistas tem problemas de coluna.

A grua com cadeira melhorou a postura e a forma de se trabalhar é tranquila, pois o eletricista faz a aproximação do potencial elétrico, equaliza com a fita, chega onde está o problema e faz a troca dos espaçadores, com a linha ligada. Caso ele passe mal, pode-se recolher a grua de forma rápida e prestar o socorro rapidamente. Antes, outro eletricista tinha que subir na torre para salvar o colega e realizar o resgate. Com a escada se levava até 30 dias para trocar 50 espaçadores; com a corda e a bicicleta, caiu para seis dias de trabalho, e agora com a grua, são 25 minutos para trocar um espaçador.

$\mathrm{O}$ custo médio para se trabalhar com seis eletricistas era de $\mathrm{R} \$ 28$ mil (pelo método da corda), para troca de 50 espaçadores durante 10 dias. Com a utilização da grua isolante o custo caiu para $\mathrm{R} \$ 12$ mil, com apenas 05 eletricistas e 05 dias. 
Figura 1 - Espaçador Quádruplo - LT Tucuruí, Vila do Conde 1.

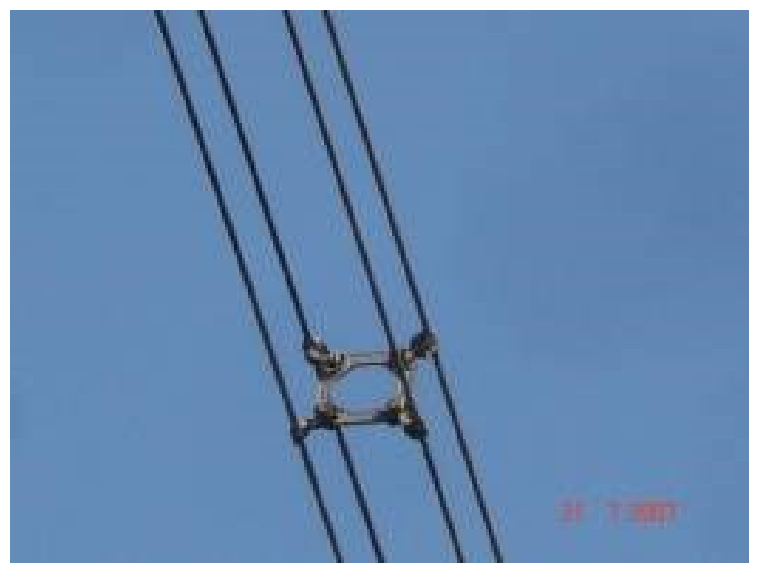

Fonte: Arquivo pessoal.

\section{DESENVOLVIMENTO}

A Eletronorte possui cerca de 12.000 mil espaçadores distribuídos em 751 vãos de torres, entre os municípios de Tucuruí e Barcarena.

Para manter em funcionamento parte desses mais de $10.000 \mathrm{~km}$ de linhas, os eletricistas cumprem um plano anual de manutenção preventivo e corretivo, dentre várias atividades destaca-se a substituição de espaçadores nos cabos condutores em 500.000 volts, em regime de linha viva. Se o trabalhador não der atenção à postura, seja por negligência ou dificuldades existentes no trabalho, há a necessidade de melhorar a relação entre e o meio em que executa as suas atividades (WISNER, 1994).

Analisando criticamente o processo de manutenção de LT'S, especificamente em espaçadores, verificamos que a atividade em si, sempre foi muito penosa, pois constam em registros fotográficos, que os eletricistas mais antigos utilizavam escadas pesadíssimas (Figura 2) para acessar os cabos condutores, sem contar com arranjos (bicicletas com roldanas), que eram utilizados por alguns eletricistas que tinham dificuldade em se deslocar pelos cabos condutores.

Figura 2 - Escada isolante utilizada para entrada no potencial. 


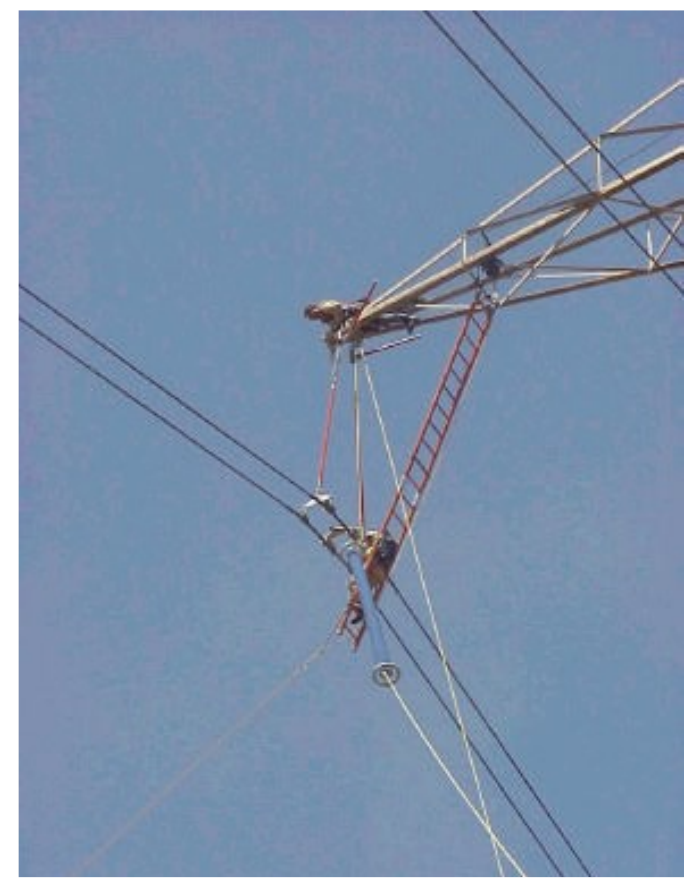

Fonte: Arquivo pessoal.

Essa espécie de bicicleta (Figuras 3 e 4) era puxada por outros eletricistas em solo, até o ponto da intervenção, ficando extremamente desgastante tanto para o eletricista do potencial, como para quem puxava isso sem contar o retorno para a torre. Frequentemente, eram relatados casos de estafa do eletricista nos cabos condutores, ocasionando um complicado resgate do mesmo. Essa prática durou muitos anos, até que começaram os testes com a corda de polipropileno para acesso ao potencial elétrico.

Figuras 3 e 4 - Método antigo - equipe de solo puxando eletricistas na "cadeirinha".
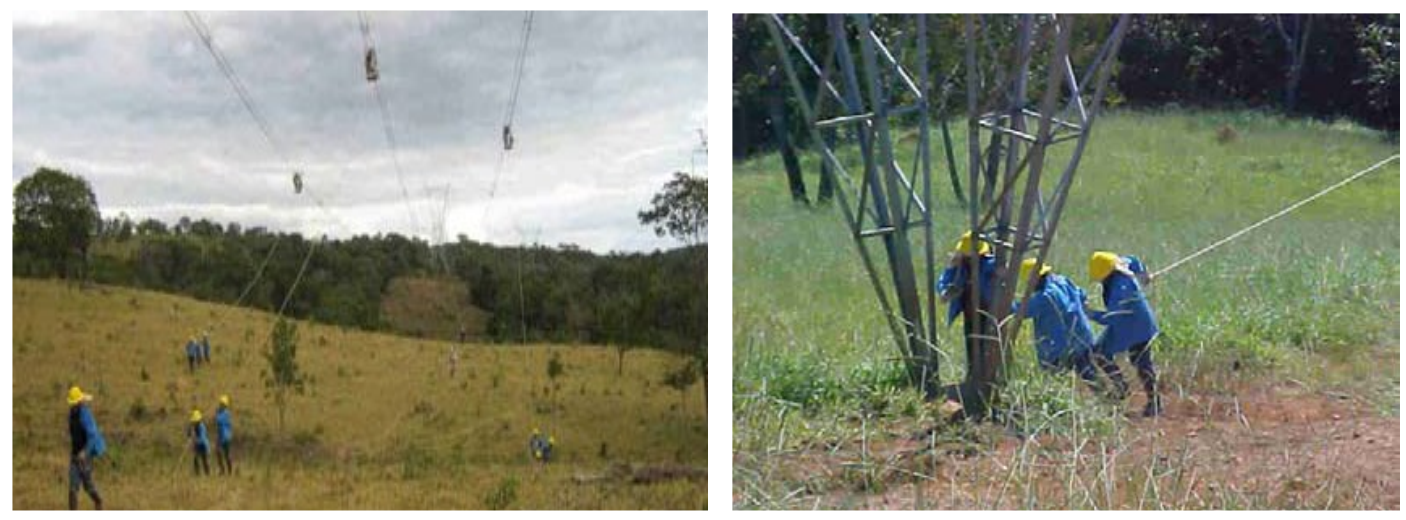

Fonte: Arquivo pessoal.

A corda, sob certos e rigorosos cuidados, mostrou-se bastante eficiente, eliminando a escada e aliviando o esforço dos eletricistas na instalação e desinstalação da mesma. Ela deve ser testada em laboratório (Figuras 5 e 6), para sua liberação de uso. 
Figuras 5 e 6 - Ensaio de corrente de fuga em corda sintética.
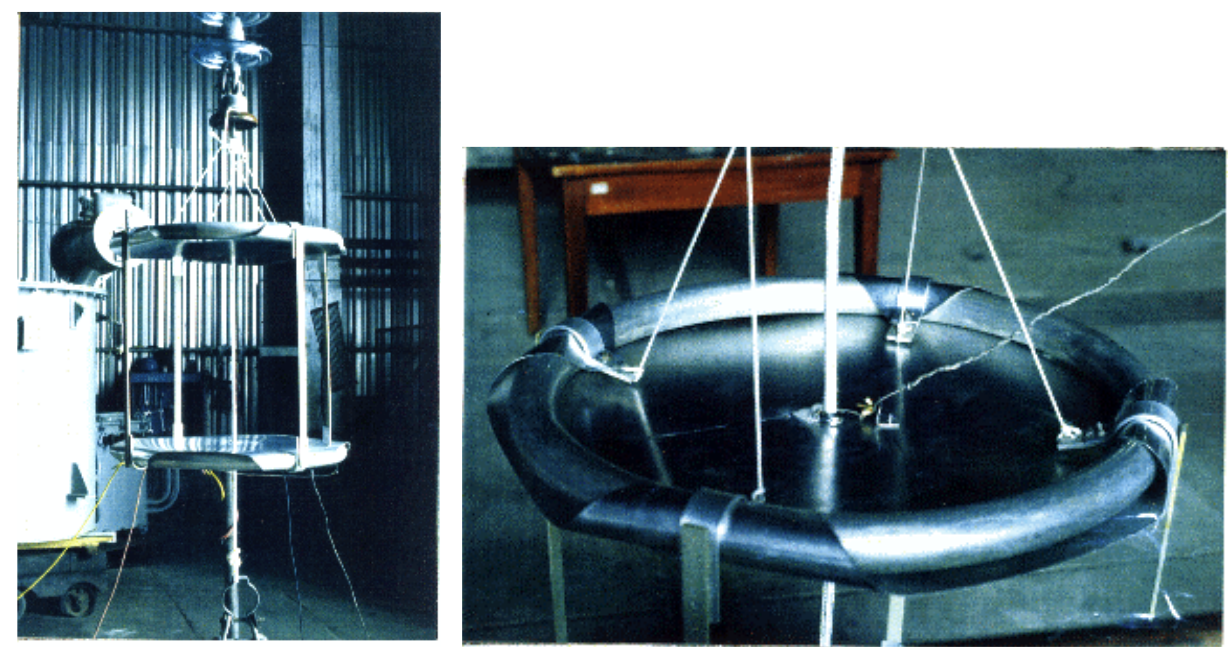

Fonte: Arquivo pessoal.

Só que a corda, tinha algumas restrições quanto à permanência diretamente no potencial. Ela era liberada, segundo normas técnicas da ABNT NBR 13.018, para toques eventuais, e na prática ficava alguns segundos em contato direto, até o eletricista desamarrá-la do cinto.Como o advento da corda (Figura 7) foi revolucionário, mas tínhamos a questão da segurança, inserimos dois bastões separadores isolantes entre a corda e o cinto do eletricista, para evitar o contato da mesma com o ponto energizado, fato esse que resolveu o problema do contato direto, mas obrigava o eletricista a um grande deslocamento (figura 8), caso o espaçador com anomalia fosse no meio do vão, pois a corda não poderia ser utilizada para descida de rapel, como fazíamos.

Durante a manutenção de uma postura corporal, utiliza-se a coluna vertebral como principal estrutura de transmissão de peso para o corpo humano, capaz de sustentar grandes cargas, certificando a proteção da medula espinhal, associada com a manutenção do equilíbrio e apoio corporal (GRIEVE, 1994). Ambos os procedimentos (escada e corda), exigiam muito da coluna vertebral dos eletricistas, principalmente pela manutenção do deslocamento nos cabos condutores, onde a mesma era mantida curvada ou em flexão até a chegada no ponto de intervenção.

Figura 7 - Entrada no potencial elétrico - via corda.

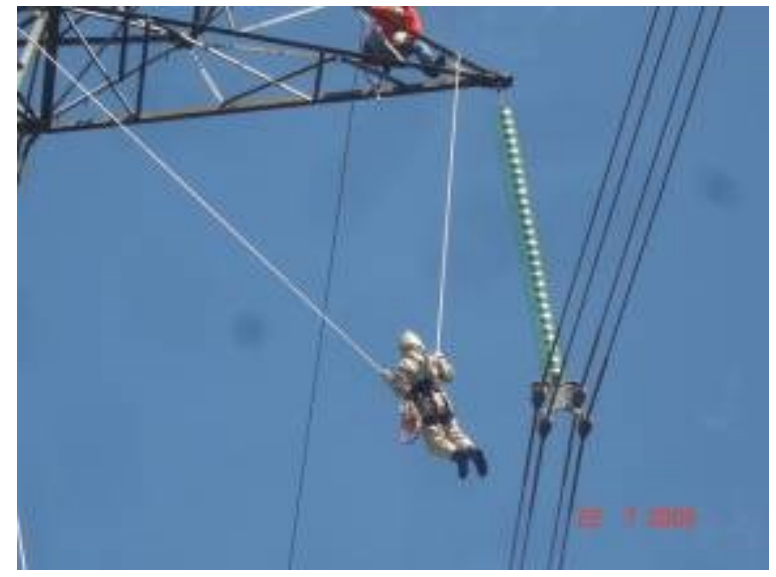

Fonte: Arquivo pessoal. 
Figura 8 - Deslocamento nos cabos.

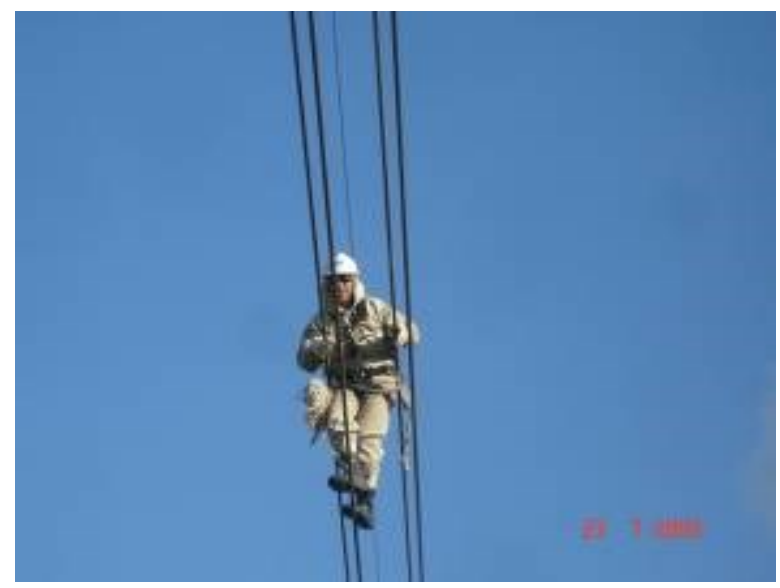

Fonte: Arquivo pessoal.

\subsection{Ações Preventivas/Corretivas}

Foi utilizada a análise ergonômica em conjunto com a metodologia CAPDo (sequência de ações para melhoria de resultado, através da eliminação de problemas - figura 9), para identificação e tratamento das causas desse problema.

Figura 9, Metodologia CAP Do (Check, Action, Plan e Do). Análise Ergonômica e Metodologia CAPDo

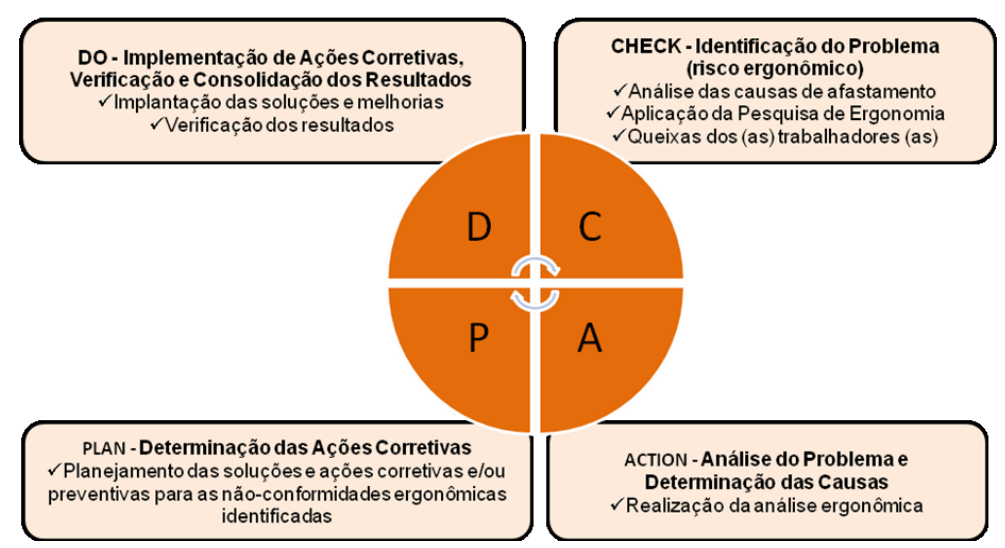

Fonte: Arquivo pessoal.

\subsubsection{Etapa Check (Identificação do Problema)}

Foram ouvidas as principais queixas dos eletricistas, sempre que uma atividade desse porte era programada.As queixas eram relatadas nas reuniões de planejamento de serviço, e nas avaliações pós-atividade, onde era comum a reclamação do "caminhar" nos cabos, principalmente quando os espaçadores estavam no meio do vão, ou seja, o eletricista tinha que subir na torre, se balançar com um pêndulo de cordas da torre para os cabos 
condutores, equalizar o potencila elétrico, realizar o deslocamento entre os cabos condutores e finalmente realizar a manutenção na peça avariada.

\subsubsection{Etapa Action (Análise do Problema e Determinação das Causas)}

A principal mudança deveria ser na forma de acesso (Figura 10) do eletricista ao potencial ou ao ponto de intervenção, pois até ele chegar no espaçador, ele já teria passado por várias etapas extremamente cansativas.

Existiam 03 etapas (escalada, entrada no potencial e deslocamento nos cabos), que poderiam ser reavaliadas ou eliminadas, se conseguissemos levar o eletricista diretamente no ponto final de intervenção.

Como a atividade necessariamente deveria ser em linha viva, pela impossibilidade de desligamento da linha de transmissão, precisaríamos de um meio de içar o mantenedor com algum equipamento isolante e de forma segura.Como a lança do guindaste é metálica, pesquisamos na fabricante Ritz (principal fabricante de ferramentas de linha viva), se possuía algo que nos atendesse.E nos deparamos com uma extensão isolante para grua, que poderia ser conectada na ponta da lança metálica do guindaste, e manteria o isolamento do caminhão com o ponto energizado.Nessa extensão poderia ainda ser instalada uma cadeira isolante onde o eletricista ficaria confortavelmente sentado para qualquer intervenção no sistema.

Verificamos também que o eletricista fica exposto diversas vezes a posturas inadequadas, tanto no deslocamento entre os cabos, quanto na posição sentado curvado para frente (Figuras 11 e 12).

Figura 10 - Entrada no potencial - Pêndulo.

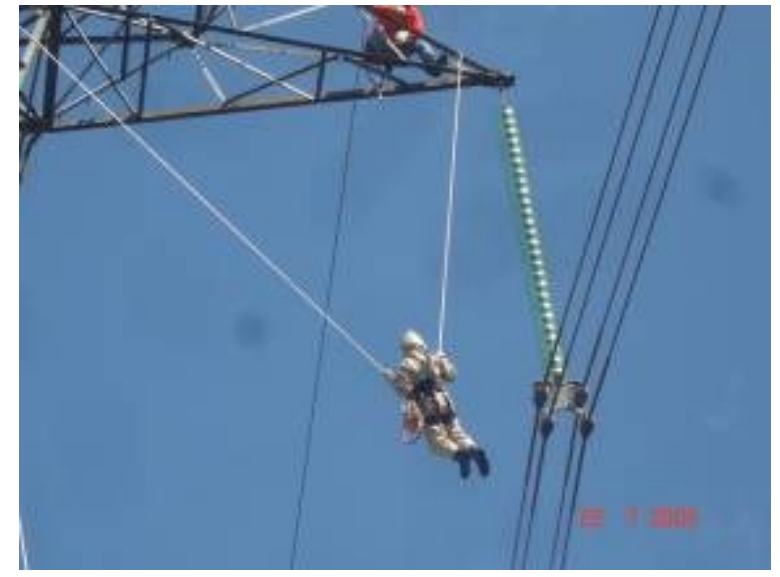

Fonte: Arquivo pessoal. 
Figura 11 - Deslocamento entre os Cabos.

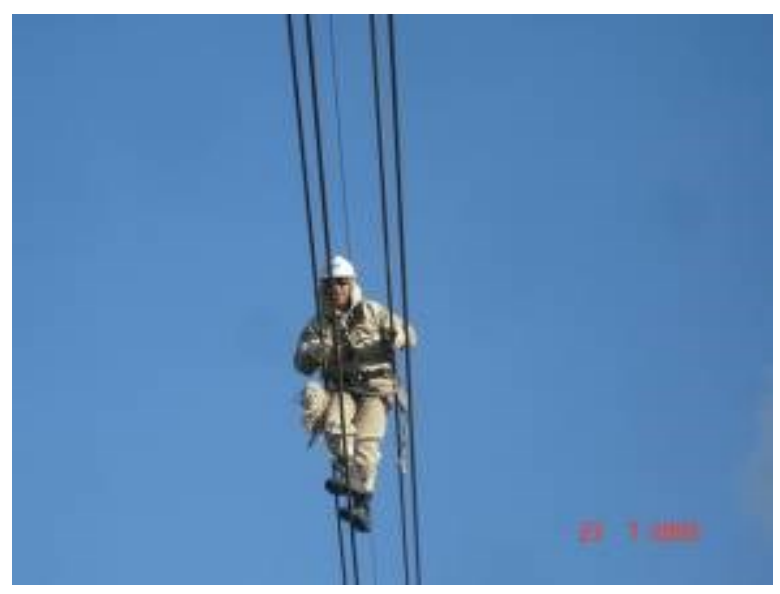

Fonte: Arquivo pessoal.

Figura 12 - Trabalho sentado curvado.

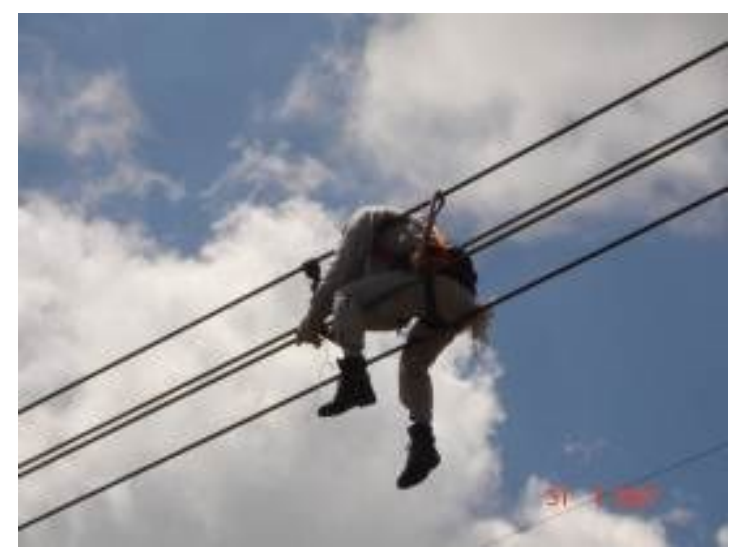

Fonte: Arquivo pessoal.

Para manter a posição de flexão do tronco, os músculos e ligamentos das costas mantêmse em contração contínua, provocando dores no pescoço e nas costas por aumentar a tensão nos discos intervertebrais e ligamentos na coluna lombar (DUL e WEERDMEESTER, 2004).

\subsubsection{Etapa Plan (Determinação das Ações Corretivas)}

Foi solicitado orçamento para aquisição de uma extensão isolante, e encaminhado para área de engenharia a proposta de melhoria, para validação da mudança de procedimento de manutenção.

Com o envolvimento da área de engenharia, foi apresentado um estudo (Figuras 13 e 14) feito pela fabricante Ritz e o Laboratório Cepel (Eletrobras), com relatório técnico (DIE12187-2006), onde são apresentados resultados e análises dos ensaios de campo e laboratório, e da modelagem computacional, do teste em uma extensão isolante para trabalhos até a tensão de 500 kv. 
Figuras 13 e 14 - Testes no laboratório da Cepel.

\subsection{Aquisição da Extensão Isolante (Fabricante Ritz)}

A extensão isolante nada mais é que 02 seções quadradas intercambiáveis para conexão à lança do guindaste, fabricadas com material isolante (Figuras 15 e 16).

\subsection{Montagem de Grua}

A seção inferior é conectada na ponta da lança do guindaste, através de pinos e parafusos(Figura 19). Na seção superior existe um suporte em liga de alumínio, que receberá a cadeira especial onde o eletricista trabalhará (Figura 20).

\subsection{Treinamento/Execução em Campo}

Os eletricistas realizaram simulações em pátio específico de treinamento, antes de efetivamente executarem a atividade em linha viva.Com uma roupa condutiva (que reproduz - Efeito da Gaiola de Faraday), o mantenedor fixa o cinto de segurança na cadeira de acesso e é içado pelo guindaste até o ponto de intervenção (Figuras 19, 20, 21 e 22), em postura adequada e segura.

Essa inovação foi implantada em 2010, na Divisão de Transmissão de Vila do Conde(Barcarena-Pará), e disseminada em seminários internos em 2011 e 2012, sendo multiplicada para outras divisões da regional Pará com o mesmo tipo de serviço, com a aquisição de mais 04 extensões isolantes tipo grua para as equipes de Marabá, Tucuruí, Altamira e Belém.

\subsection{Atendimento à Legislação}

Com a prática desse novo método de trabalho, a legislação foi atendida nos seguntes aspectos:

2.5.1. Norma Regulamentadora - NR $17-17.1$

- Adaptação das condições de trabalho às características psicofisiológicas dos trabalhadores.

- O movimento pendular que o trabalhador era submetido, amarrado em cordas, com compressão mecânica na região lombar.O deslocamento entre os cabos condutores, que exigia constante equilíbrio e esforço para manter-se ereto, com o constante risco de "virar" e ficar pendurado pelo talabarte do cinto de segurança.

\section{RESULTADOS}

Os ganhos com a aquisição da grua isolante (Figura 23) foram inúmeros, como podemos citar: aumento da segurança do eletricista, redução do esforço físico do eletricista, alcances 
diversos, variando de acordo com o comprimento da lança do caminhão utilizado, maior produtividade da equipe, com possibilidade de manutenções simultâneas no mesmo vão, em fases diferentes, maior velocidade na retirada do eletricista do potencial, em caso de contingência (desligamento da linha ou desmaio do eletricista), redução do número de eletricistas para realização da atividade, resolução de problema organizacional com os eletricistas que estavam afastados por restrição de escalada em estruturas. Com o novo método de acesso, para esse tipo de serviço, os mesmos foram reintegrados a equipe voltando as suas atividades de campo.

Na tabela 1, podemos verificar o comparativo de homem $\mathrm{x}$ hora necessários nos diferentes métodos de trabalho, para substituição de 50 espaçadores com defeito.

Tabela 1 - Comparativo homem x hora dos métodos de trabalho.

\begin{tabular}{|c|c|c|}
\hline \multicolumn{3}{|c|}{ Atividade: $\mathbf{5 0}$ espaçadores para substituição - Hipótese } \\
\hline $\begin{array}{c}\text { Método de entrada no } \\
\text { potencial }\end{array}$ & $\begin{array}{c}\text { Número de eletricistas } \\
\text { necessários }\end{array}$ & Dias de trabalho \\
\hline Escada Isolante & 8 & 25 a 30 dias \\
\hline Corda Sintética & 6 & 10 a 12 dias \\
\hline Grua Isolante & 5 & 5 dias \\
\hline
\end{tabular}

Fonte: Arquivo pessoal.

\subsection{Tempo Médio para Manutenção em 01 Espaçador - Comparativo 03 Métodos}

Para manutenção de 01 espaçador defeituoso tínhamos com o método da escada isolante um tempo médio de 02 horas.Com o advento de acesso pela corda isolante, esse tempo caiu para 50 minutos, e com a análise ergonômica temos atualmente essa medida em 25 minutos (figura 23).

\section{Figura 23 - Comparação dos tempos de manobra dos métodos de manutenção em linha viva.}

Fonte: Arquivo pessoal.

Os custos envolvidos na melhoria foram na aquisição da extensão isolante ( $R \$ 36.000,00)$. O caminhão guindaste já estava disponível na frota de veículos da Subestação.

\section{CONCLUSÃO}

Com a prática consolidada ao longo de 03 anos, as possibilidades de aplicação são diversas, além da utilização em campo na troca de espaçadores. A grua já foi utilizada com sucesso, em atividades dentro de subestações, como retirada de ponto de quente, jumpeamento de chaves seccionadoras, onde anteriormente eram utilizados os andaimes isolantes. 
As demais equipes de linha viva (Tucuruí, Marabá, Altamira e Belém), também adquiriram o equipamento e a nossa divisão (Barcarena), foi realizar treinamento para disseminação do novo método.

A ergonomia evoluiu de forma bastante consistente, passando a fazer parte do mundo do trabalho, acompanhando, em termos de desafios, as exigências do mercado laborativo de uma forma cada vez mais comum (COUTO e MORAES, 1999). Ela envolve todo o processo de relação entre o ambiente físico e também os aspectos organizacionais, e procura reduzir a fadiga, o estresse, erros e acidentes, proporcionando segurança, satisfação e saúde aos trabalhadores, durante o seu processo produtivo (IIDA, 2005).

Para realização desse projeto, vários departamentos foram envolvidos (administração aquisição, engenharia, laboratório, gerência, SESMT/CIPA), e foi possível sentir a sinergia criada para conclusão do projeto.

A ergonomia é grande aliada dos trabalhadores, principalmente nesse setor de linha de transmissão, pois temos muitas tarefas com posturas inadequadas, extenuantes, que merecem uma análise ergonômica. E com o Programa de Ergonomia que temos aqui na Eletrobras/Eletronorte, tais realidades estão sendo modificadas, buscando sempre uma produtividade saudável.

\section{REFERÊNCIAS BIBLIOGRÁFICAS}

COUTO, H. A.; MORAES, L. F. R. de. Limites do homem. Revista Proteção, São Paulo, v. 22, n. 96 , p. 38-44, dez. 1999.

DUL, J.; WEERDMEESTER, B. Ergonomia prática. Tradução: Itiro lida. São Paulo: Edgard Blücher, 2004.

GRAVES RJ, C. A.; WRIGHT, E., WATT, M., WHITE, R. Potential musculoskeletal risk factors in electricity distribuition linesman tasks. In: Robertson SA, editor. Comtemporary Ergonomics 1996. Leicester: CRC Press; 1996.

GRIEVE, G. P. Moderna Terapia Manual da Coluna Vertebral. São Paulo: Panamericana, 1994.

IIDA, I. Ergonomia: projeto e produção. São Paulo: Edgard Blücher, 2005.

PAIVINEN, M. Electricians perpections of work-related risks in cold climate when working in high places. Int J Ind Ergon. 2006.

SEELEY, P. A.; MARKLIN, R. W. Businnes case for implementing two ergonomic interventions at an electric power utility. Appl Ergon. 2003.

WISNER, A. Por dentro do trabalho - Ergonomia: método e técnica. São Paulo: Oboré, 1994. 